\title{
Research on the Architectural Culture of Jiarong Tibetan in Northwest Sichuan from the Perspective of Architectural Anthropology
}

\author{
Chaoyi You \\ Architecture and Urban Planning College of Southwest Minzu University, Chengdu, China \\ Email:651645399@qq.com
}

How to cite this paper: You, C.Y. (2020) Research on the Architectural Culture of Jiarong Tibetan in Northwest Sichuan from the Perspective of Architectural Anthropology. Open Access Library Journal, 7: e6712. https://doi.org/10.4236/oalib.1106712

Received: August 12, 2020

Accepted: August 24, 2020

Published: August 27, 2020

Copyright $\odot 2020$ by author(s) and Open Access Library Inc.

This work is licensed under the Creative Commons Attribution International License (CC BY 4.0).

http://creativecommons.org/licenses/by/4.0/

(c) (i) Open Access

\begin{abstract}
With the deepening of domestic scholars' understanding of Tibetan architecture, they have a more in-depth study of Tibetan architecture, including history, customs, religion, system, culture and so on. There are not only Weizang Tibetan area, Kangba Tibetan area and Anduo Tibetan area that we are familiar with, but also some little-known Tibetan areas, such as Jiarong Tibe$\tan$ area, Baima Tibetan area and so on. According to the current situation, the relevant scholars in the academic circles constantly put forward that the research work should be specific, that is, to explore the Tibetan architectural culture of a certain area and a certain crowd to supplement and develop the research on Tibetan architectural culture, so that Chinese architectural culture can be more colorful. Therefore, in this article, it will expound the Jiarong Tibetan and its background factors-natural environment and social environment, and then based on the perspective of Architectural Anthropology, it will elaborate its architectural features and cultural connotation. At the same time, a new perspective of interdisciplinary research is put forward; that is, the methods of architecture and anthropology should be comprehensively applied to study the architectural culture of Jiarong Tibetan in Northwest Sichuan to obtain more in-depth research results.
\end{abstract}

\section{Subject Areas}

Anthropology, Art, Culture, Sociology

\section{Keywords}

Architectural Anthropology, Northwest Sichuan, Jiarong Tibetan, Rchitectural Culture 


\section{Introduction}

Architecture has been playing an indispensable role in human life in the field of anthropology. The concept of architectural anthropology came into being in the 1950s. In the Dimension of Architectural Anthropology_on the Relationship between Cultural Anthropology and Architecture, it is said that "architectural anthropology is to apply the research methods and results of cultural anthropology to the field of architecture" [1]. Architectural anthropology focuses on the study of human natural environment, social economy, religious culture, folk customs and the relationship between people, emphasizes people-oriented, and explores the deep value from the perspective of cultural evolution. Therefore, in this paper, based on the field research and the fieldwork done by other relevant scholars in Danba County of Ganzi Prefecture and Wen, Li and Mao Countries of Aba Prefecture, from the special perspective of architectural anthropology, the architectural culture of Jiarong Tibetan in Northwest Sichuan is analyzed, so as to embody the deepening and comprehensiveness of interdisciplinary research.

\section{Architectural Anthropology}

Architectural anthropology appeared in the western architectural circles in the second half of the 20th century. Architectural anthropology is to examine architecture from the perspective of anthropology. According to Chang Qing, "the essence of architectural anthropology is a perspective and method that emphasizes the observation, experience and analysis of the custom background and cultural meaning of architectural phenomena in a specific environment" [2]. Architectural anthropology emphasizes the study of human natural environment, social economy, religious culture, folk customs and the relationship between people, which constitute the social and cultural background of the building and are expressed through the site selection, layout, space and decoration of the building. Architectural anthropology mainly studies the relationship between architecture and nature, between architecture and society, and between architecture and human beings. These relationships do not exist in isolation, but interact with each other and integrate into various architectural cultural forms harmoniously.

\section{Overview of Jiarong Tibetan in Northwest Sichuan}

\subsection{Brief Introduction of Jiarong Tibetan}

It is proposed in the book "Mo Erduo sacred mountain" that "Jiarong" is the abbreviation of Tibetan "jia mo cha wa rong" [3]. A sacred mountain located between Xiaojin county and Danba county is called "Mo Erduo holy mountain", and its Tibetan name is "si ba jia er mo". Therefore, people living there call the area around thousands of miles as "jia mo cha wa rong". "Chawa" means "hot valley zone" in Tibetan. "Rong" refers to the agricultural production area [4], where the main production includes wheat, highland barley and other crops. "Jiarong" is a place name combined with many meanings, including geographi- 
cal environment and production mode. With its unique geographical location and diverse national culture, Jiarong Tibetan has the characteristics of richness and uniqueness.

\subsection{Natural Environment of Jiarong Tibetan}

\subsubsection{Topographic Features}

In Jiarong Tibetan inhabited area, the altitude is high and there are many mountains and rivers. The rest of the mountains spread around with Qionglai mountain range and Daxueshan mountain range as the backbone, thus forming the mountain valley landform in this area. These mountains range from north to south are Minya Konka, Zhegu mountain, Balang mountain, Siguniang mountain, etc., with an altitude of more than 4000 meters, becoming the natural dividing line of the region. At the same time, there are many tributaries of Minjiang River and Dadu River.

\subsubsection{Geography and Climate}

Jiarong Tibetan inhabited area is located in the special plateau mountainous area of Hengduan Mountain area, belonging to subtropical plateau monsoon climate. The climate characteristics are as follows: cold in winter, hot in summer, more wind and less rain, large temperature difference between day and night, long sunshine time, etc. The annual average rainfall in this region is less than 700 $\mathrm{mm}$, and the rainfall is mainly concentrated in summer, while it is dry in winter. In addition, the sunshine in this area is strong and lasting for a long time, and the temperature difference between day and night is large. The temperature in the daytime is between $30^{\circ} \mathrm{C}$ and $40^{\circ} \mathrm{C}$ and the temperature at night is between $-10^{\circ} \mathrm{C}$ and $-15^{\circ} \mathrm{C}$.

\subsubsection{Resources}

At the same time, in Jiarong Tibetan area, there are dense vegetation coverage, rich animal and plant resources, many national protected animals and precious Chinese herbal medicines and fungi. It can be learned from the exploration of resources in this area from the research on the architectural culture of Jiarong Tibetan village that the largest amount of known mineral resources in this area is mica, and a small amount of iron and tin are also found. Due to the production of gold, large and small Jinchuan basins are famous for large and small Jinchuan [5].

\subsection{The Social Environment of Jiarong Tibetans}

\subsubsection{Historical Background}

In the article Research on Tibetan Dwellings in Ganzi Prefecture, Sichuan Province, Xie Jiao said that Jiarong Tibetans originated from the ancient Qiang people. In ancient times, the ancient Qiang people mainly lived in Gansu and Qinghai in Northwest China, mainly nomadic life. With the change of natural conditions, these Qiang people began to migrate southward along the Hengduan Mountains of the Qinghai Tibet Plateau in the middle Neolithic period, and 
gradually concentrated in the Qiangtang area in northern Tibet and the upper reaches of the Minjiang River. At that time, productivity was low, and different tribes often fought. Among them, the defeated Qiang people, the "geji people", migrated southward to the middle and upper reaches of Dadu River to the west of Dengxia mountain from the middle to the end of Neolithic [6].

\subsubsection{Chieftain System}

The chieftain system began in 1336 in Yuan Dynasty, which was a feudal serf system. The chieftain system has a strict hierarchy and organizational form. From the chieftain, the ruler of a certain area, all the lower strata had their rights and obligations [6].

\subsubsection{Religious Influence}

In Tibet, all people believe in religion, and religion has become an important part of local people's life [5]. Before, there was no religion in Jiarong Tibetan area, only primitive worship. In the period of Shundi in the Eastern Han Dynasty, "Benbo religion", the primitive religion in Tubo area, was introduced into Jiarong Tibetan area from Tubo and gradually developed. As a polytheistic sect, Benbo religion believes that all things have spirits, believes that gods are everywhere, and worships heaven and earth, sun and moon, stars, thunder and lightning, mountains and rivers, plants, animals and so on. Buddhism was introduced into Tibetan areas in the seventh century, and then developed into Tibetan Buddhism. At the end of the eighth century, because the local Bon temples took part in the rebellion, the measures to eliminate Bon religion and promote Buddhism were implemented in today's Ganzi and Aba after the Jinchuan campaign. After the end of the war, some temples were converted to the Yellow Sect or "Gelugpa" of Tibetan Buddhism.

\subsubsection{Primitive Worship}

People in Jiarong Tibetan area in Western Sichuan have a very strong worship psychology for heaven, earth, mountains and rivers, animals and plants. With the development of history, these worship psychology evolved into related behaviors, and then affected the changes of architecture and were endowed with sacred symbolic significance. According to different objects, primitive worship can be divided into nature worship, reproduction worship and totem worship. Among them, nature worship includes mountain god worship, water god worship and fire god worship.

\subsubsection{Folk Customs}

\section{1) Diet}

The limitation of geographical conditions and the lack of living resources in Tibetan areas have created the main industries in Northwest Sichuan. Milk, butter tea and other foods are indispensable in people's daily diet. At the same time, they use livestock to engage in farming and breeding and other production, and has been highly efficient development. 


\section{2) Festivals}

There are many local festivals in Jiarong Tibetan area. The Spring Festival of the Tibetan year and the sacrifice to the God of Murdo are the most important festivals. People usually get together and dance Guozhuang to celebrate many other festivals. The Spring Festival of the Tibetan year is roughly the same as the Spring Festival of the Han nationality, which is the most solemn festival in the local area. In the festival of Murdo, activities in the form of temple fairs and fairs are held, which are attended by local Tibetans, people of other nationalities and tourists.

\section{3) All kinds of taboos}

There are many taboos in Jiarong Tibetans' marriage, building houses, and getting sick. Among them, there is a certain saying about the footstone they put beside the fire pool. Because Jiarong Tibetans generally believe in the kitchen god, they set up a stone slab on the back of the three shelves of the Huotang as a place to worship the kitchen god. You can't put your feet here [5]. In addition, people who believe in the Yellow religion turn the scripture clockwise, while those who believe in the underworld turn it counter clockwise.

\section{Characteristics and Cultural Connotation of Jiarong Tibetan Architecture}

In the construction of Jiarong Tibetan area, local stone is usually used, and timber is used as beam and loess as binder. On the basis of the original materials, the current building materials add steel, cement, concrete and other modern materials. The whole building is ladder like, with wide wall bottom and narrow top. The buildings in Jiarong Tibetan area are divided into residence, chieftain's village, temple, Lama pagoda and watchtower according to their functions and classes.

\subsection{Residence}

Qiong cage style residence is the earliest living form of Jiarong Tibetan. When they choose the address of the house, they combine the environment and respect the nature as the first principle. Before preparing to build houses, Tibetans should ask "Gongba" to make divination. When making divination, Gongba needs the date of birth and the eight characters of the family and the soil on the foundation of the house. Whether the house can be built and when to start construction should be decided after Gongba's divination. If it's not good divination, maybe people need to choose to build houses elsewhere. At the same time, the location of the house should ensure that the local sacred mountain can be seen when standing on the roof of the house after completion, which is a cultural feature of Tibetan primitive worship [5].

\subsection{Chieftain's Official Village}

As a place where chieftains live, work and play, chieftain's official village is also a 
symbol of their power, prestige and wealth. The chieftain's village is very defensive. The official village is piled up with solid earth wall and stone wall, which has high security. The site selection of chieftain's village is affected by cultivated land, terrain, water source, light and other factors. In addition, chieftain's villages are all located in the center of Tibetan villages, and are the center of social activities in this area.

\subsection{Temple}

Stone, wood and earth are the main building materials of temples in Tibetan Buddhism. The exterior walls of Tibetan Buddhist temples are mainly in red, white and yellow colors. Most of them have wall paintings, which draw a variety of Buddhist stories to facilitate the illiterate believers to understand the origin of religion. As the carrier of traditional culture, the architectural culture of Tibetan Buddhist temples embodies the culture and spirit of Tibetan people.

\subsection{Lama Pagoda}

Lama pagoda is composed of four parts: tower base, tower body, tower neck and tower sha. The tower body is called "tower belly", and tower neck is called "phase wheel". The shape of the tower base is usually square, octagonal, circular or polygonal; the shape of the tower body is similar to an inverted bowl, and the plane is round; the tower neck has 13 layers, also known as "thirteen days", which is divided upward; tower sha is composed of the sun and the moon, the pagoda and the umbrella cover. The top of the Lama pagoda is gorgeous and diverse. Small Lama pagodas are usually located at the entrance of the village, while higher level Lama pagodas are located in the high-lying areas of the village, and they are usually hung with Sutra banners, which are used as places to worship or transfer scriptures.

\subsection{Watchtower}

Danba County of Ganzi Tibetan Autonomous Prefecture and Wen, Li and Mao counties of Aba Tibetan and Qiang Autonomous Prefecture are the main distribution areas of watchtower in Jiarong Tibetan area of Northwest Sichuan [7]. The watchtower in Jiarong Tibetan area is basically made of local stone carving. The watchtower is trapezoidal in shape, that is, its shape is gradually reduced from bottom to top, with strong stability and flexibility. In history, watchtower has the functions of residence, storage, defense in wartime, religious sacrifice and so on. In addition, Mr. Yang Jiaming pointed out in the investigation that "in the Danba area, watchtower is the witness of the birth and growth of men. In the past, whenever a boy was born in Danba area, people prepared materials such as stones and wood to build watchtower. And every year the boy grew up, the watchtower was added a layer until he was 18 years old and an adult ceremony was held under the built watchtower" [8]. In addition, in the Jiarong Tibetan area, there are also the saying of the male watchtower and the female 
watchtower. The male watchtower has a symbol of male genitalia, and each floor of the female watchtower has grooves. Reproductive worship plays an important role in the traditional culture of Jiarong Tibetan area in Northwest Sichuan Province, which reflects the Tibetan people's desire for reproduction and a prosperous population.

\section{Conclusion}

It can be seen from the perspective of architectural anthropology that the topography and folk customs of Jiarong Tibetan villages in Northwest Sichuan are different. Therefore, the functions of various buildings in villages are different, and the forms of buildings have their own characteristics. However, in essence, the emergence of any situation is not isolated or accidental, but the product of the integration of geographical location, climate conditions, historical background, political economy, living customs, religious beliefs, culture and art and many other complex factors. It is the natural geographical conditions that lead to the regional characteristics of Jiarong Tibetan village, and the historical factors lead to the hierarchical system reflected in the layout of the village and the internal functions of the buildings. Because of the integration and superposition of these factors, the architectural culture of Jiarong Tibetan in Northwest Sichuan has more profound historical value and research significance. Therefore, this author believes that the breadth and depth of interdisciplinary research on architecture have breakthrough practical significance for research work.

\section{Conflicts of Interest}

The author declares no conflicts of interest regarding the publication of this paper.

\section{References}

[1] Zhang, X.C. (1999) Dimension of Architectural Anthropology: On the Relationship between Cultural Anthropology and Architecture. New Architecture, No. 4, 67-69.

[2] Chang, Q. (2008) Anthropological Perspective of Architecture. Architect, No. 6, 95-101

[3] Lin, J.H. (2013) Jiarong's Cultural Symbols. Journal of Sichuan University for Nationalities, 22, 1-7.

[4] Liu, X. (2015) Study on the Architectural Form and Ecological Performance of Traditional Tibetan Dwellings in Jiarong, Northwest Sichuan. Xi'an University of Architecture and Technology, Xi'an.

[5] Mao, L.H. (2005) Research on the Architectural Culture of Jiarong Tibetan Village. Southwest Jiaotong University, Chengdu.

[6] Xie, J. (2010) Research on Tibetan Dwellings in Ganzi Prefecture, Sichuan Province. Xi'an University of Architecture and Technology, Xi'an.

[7] Li, X.Q. (2013) Research on Gaodiao Architectural Culture of Jiarong Tibetan Village in Tibetan Yi Corridor Area. Xi'an University of Architecture and Technology, Xi'an.

[8] Yang, J.M. (2004) An Overview of Architectural Culture of Dan Ba Gu Diao. Chinese Tibetology, No. 2, 93-103. 